\title{
ARTICLE
}

\section{LW-213 induces cell apoptosis in human cutaneous T-cell lymphomas by activating PERK-eIF2 $\alpha-\mathrm{ATF} 4-\mathrm{CHOP}$ axis}

\author{
Xiao-xuan $\mathrm{Yu}^{1,2}$, Meng-yuan Zhu' ${ }^{1}$, Jia-rong Wang ${ }^{1}$, Hui Li ${ }^{1}$, Po Hu${ }^{1}$, Ying-jie Qing ${ }^{1}$, Xiang-yuan Wang ${ }^{1}$, Hong-zheng Wang ${ }^{1}$, \\ Zhan-yu Wang ${ }^{1}$, Jing-yan $\mathrm{Xu}^{3}$, Qing-long Guo ${ }^{1}$ and Hui Hui ${ }^{1}$
}

\begin{abstract}
Cutaneous T-cell lymphoma (CTCL) is characterized by a heterogeneous group of extranodal non-Hodgkin lymphomas, in which monoclonal T lymphocytes infiltrate the skin. LW-213, a derivative of wogonin, was found to induce cell apoptosis in chronic myeloid leukemia (CML). In this study, we investigated the effects of LW-213 on CTCL cells and the underlying mechanisms. We showed that LW-213 (1-25 $\mu \mathrm{M}$ ) dose-dependently inhibited human CTCL cell lines (Hut-102, Hut-78, MyLa, and HH) with $\mathrm{IC}_{50}$ values of around $10 \mu \mathrm{M}$, meanwhile it potently inhibited primary leukemia cells derived from peripheral blood of T-cell lymphoma patients. We revealed that LW-213-induced apoptosis was accompanied by ROS formation and the release of calcium from endoplasmic reticulum (ER) through $\mathrm{P}_{3} \mathrm{R}-1$ channel. $\mathrm{LW}-213$ selectively activated CHOP and induced apoptosis in Hut-102 cells via activating PERK-elF2a-ATF4 pathway. Interestingly, the degree of apoptosis and expression of ER stressrelated proteins were alleviated in the presence of either $\mathrm{N}$-acetyl cysteine (NAC), an ROS scavenger, or 2-aminoethyl diphenylborinate (2-APB), an $\mathrm{IP}_{3} \mathrm{R}-1$ inhibitor, implicating ROS/calcium-dependent ER stress in LW-213-induced apoptosis. In NOD/SCID mice bearing Hut-102 cell line xenografts, administration of LW-213 (10 mg/kg, ip, every other day for 4 weeks) markedly inhibited the growth of Hut-102 derived xenografts and prolonged survival. In conclusion, our study provides a new insight into the mechanism of LW-213-induced apoptosis, suggesting the potential of LW-213 as a promising agent against CTCL.
\end{abstract}

Keywords: CTCL; LW-213; wogonin; flavonoids; ER stress; ROS; calcium; apoptosis; NAC; 2-APB

Acta Pharmacologica Sinica (2021) 42:290-300; https://doi.org/10.1038/s41401-020-0466-7

\section{INTRODUCTION}

Cutaneous T-cell lymphoma (CTCL) represents a heterogeneous group of extranodal non-Hodgkin lymphomas in which monoclonal T lymphocytes infiltrate the skin [1, 2]. Mycosis fungoides and Sézary Syndrome (SS) are the most common types of CTCL [3]. Characterized by a wide variety of clinical findings and histological findings, $C T C L$ often demonstrates skin localization and progression to erythroderma, with subsequent involvement of the lymph nodes, peripheral blood, and visceral organs, such as the spleen [4]. Given the development of multidrug resistance or drugrelated adverse reactions during treatment, the prognosis of $\mathrm{CTCL}$ remains poor, with a 5 -year survival rate of $<50 \%[5,6]$.

As a crucial organelle in eukaryotic cells, the endoplasmic reticulum (ER) regulates a wide array of fundamental cellular processes, including transmembrane and secretory protein folding, lipid biosynthesis, drug detoxification, calcium storage, and signaling [7]. Hypoxia, oxidative disorder, changes in $\mathrm{pH}, \mathrm{Ca}^{2}$ + dislocation, starvation, hypoglycemia, ATP depletion, and viral infection impact ER homeostasis [8]. All these events can disturb correct protein folding, leading to the accumulation of misfolded or unfolded proteins and the evolution of a stress-induced signaling cascade signal transduction pathway called the unfolded protein response (UPR) [9]. Once misfolded proteins accumulate beyond the tolerance threshold of the ER, a cell will undergo apoptosis [10]. The UPR has been documented in most major types of human cancer, including T-cell lymphoma, suggesting it has a significant role in tumor progression [11-13]. This feature endows cancer cells with vulnerabilities that can be harnessed to secure a therapeutic advantage. Unfolded and misfolded proteins that accumulate in the ER can be detected by three ER transmembrane sensors, inositol requiring enzyme1a, protein kinase RNA-like ER kinase (PERK), and activating transcription factor 6 [8].

PERK is an ER transmembrane protein that is activated by oligomerization and autophosphorylation in response to UPR triggering, and it is required at the ER-mitochondrial constant sites to convey apoptotic signalings after reactive oxygen species (ROS)-based ER stress [14, 15]. Once activated, PERK reduces mRNA translation and prevents the arrival of new proteins into the ER compartment, which is mediated by phosphorylation of

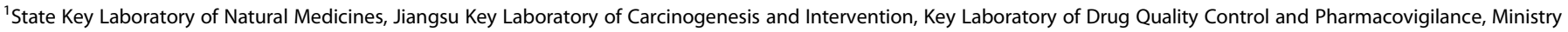

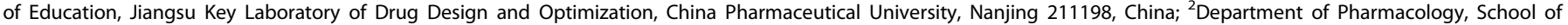

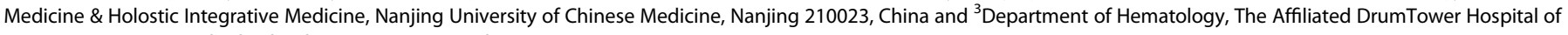
Nanjing University Medical School, Nanjing 210000, China

Correspondence: Qing-long Guo (anticancer_drug@163.com) or Hui Hui (moyehh@163.com)

These authors contributed equally: Xiao-xuan Yu, Meng-yuan Zhu

Received: 20 April 2020 Accepted: 22 June 2020

Published online: 3 August 2020 
eukaryotic translation initiation factor 2 (elF2a). Phosphorylated elF2 $a$ blocks the recycling of elF2 $a$ in its active GTP-bound state, which is needed for starting polypeptidechain synthesis, leading to the attenuation of general protein translation [16]. However, elF2a phosphorylation also regulates the expression of activating transcription factor 4 (ATF4), a member of the ATF/CREB family of transcription factors that regulates the expression of genes involved in the restoration of normal cellular homeostasis $[16,17]$. The transcription factor ATF4 binds the promoter region of the proapoptotic C/EBP homologous protein (CHOP) gene, increasing its mRNA expression and subsequently its protein levels [18]. Once ER stress is irreversible, ATF4-CHOP activation can induce the apoptotic pathway [19].

Natural compounds, which are characterized by antioxidant, anticarcinogenic, antimutagenic, and detoxification properties, constitute a promising intervention to prevent carcinogenesis $[20,21]$. Several natural compounds, such as curcumin, resveratrol, green tea polyphenols, garcinia, and tocotrienols, induce apoptosis in cancer by modulating ER stress [22-26]. LW-213 is a derivative of wogonin that induces $\mathrm{G} 2 / \mathrm{M}$ cell cycle arrest and apoptosis in human breast cancer and chronic myeloid leukemia (CML) $[27,28]$. In this study, we examined the effect of LW-213 on CTCL apoptosis and the PERK-elF2a-ATF4/CHOP signaling axis. Moreover, we established a NOD/SCID mouse model bearing Hut102 tumors to further verify the anticancer effect and potential mechanism of LW-213.

\section{MATERIALS AND METHODS}

\section{Compounds and reagents}

LW-213 was synthesized from chrysin (Shanxi Ciyuan Biotech Co., Ltd., China). The final compound was a yellow solid powder with a purity $>99.5 \%$. For in vitro experiments, LW-213 was dissolved in dimethyl sulfoxide (DMSO, Sigma-Aldrich, Missouri, USA) at a concentration of $0.02 \mathrm{M}$, stored at $-80^{\circ} \mathrm{C}$ and diluted to a suitable concentration with RPMI-1640 medium (Gibco, California, USA). Cells treated with the highest concentration of DMSO were used as controls in the indicated experiments.

For in vivo experiments, LW-213 was prepared as an intraperitoneal injection administration formulation by Dr. Xue Ke at the College of Pharmacy, China Pharmaceutical University. NAB was purchased from Aladdin (Shanghai, China), and mice were injected intraperitoneally.

2-Aminoethyl diphenylborinate (2-APB) was obtained from CSNpharm (Chicago, USA). N-acetyl cysteine (NAC) was obtained from Beyotime (Nanjing, China).

\section{Cell cultures}

The human CTCL cell lines Hut-102, Hut-78, MyLa, and HH were purchased from the Cell Bank of the Shanghai Institute of Biochemistry \& Cell Biology. All the cell lines were authenticated by short tandem repeat analysis performed by the suppliers. Then, the cells were expanded and stored in liquid nitrogen upon receipt, and each aliquot was passaged fewer than 25-30 times in our laboratory. Cells were cultured in RPMI-1640 medium supplemented with $10 \%$ heat-inactivated FBS (Thermo Fisher Scientific, Massachusetts, USA), $100 \mathrm{U} / \mathrm{mL}$ benzyl penicillin, and $100 \mathrm{U} / \mathrm{mL}$ streptomycin in a humidified environment (Thermo Fisher Scientific) with $5 \% \mathrm{CO}_{2}$ at $37^{\circ} \mathrm{C}$.

Primary lymphoma cells derived from lymphoma patients (The First Affiliated Hospital of Nanjing Medical University, Nanjing, China) were collected using lymphocyte-monocyte separation medium (Jingmei, China). Primary lymphoma cells and cell lines were cultured in RPMI-1640 medium supplemented with 10\% heat-inactivated FBS (Thermo Fisher Scientific, Waltham, MA), 100 $\mathrm{mg} / \mathrm{mL}$ benzyl penicillin, and $100 \mathrm{mg} / \mathrm{mL}$ streptomycin in a humidified environment (Thermo Fisher Scientific) with $5 \% \mathrm{CO}_{2}$ at $37^{\circ} \mathrm{C}$.
Cell viability assay

Hut-102, Hut-78, MyLa, and HH cells $\left(1 \times 10^{4}\right.$ cells/well) were seeded in 96-well plates, and then treated with LW-213 at various concentrations for 12 or $24 \mathrm{~h}$. Then, $20 \mu \mathrm{L}$ CCK8 solution was added to each well and incubated for $4 \mathrm{~h}$. Cells treated with equivalent amounts of DMSO (0.1\%) were used as a negative control. The absorbance was read at $450 \mathrm{~nm}$ with a SynergyTM HT multimode reader (BioTek, Vermont, USA). The average value of the optical density of five wells was used to determine cell viability by the following formula:

Survival rate $(\%)=O D_{\text {(treatment group) }} / O D_{\text {(control group) }} \times 100 \%$.

The $\mathrm{IC}_{50}$ value was defined as the concentration that caused a $50 \%$ inhibition in cell viability and was calculated by the logit method.

Detection of the intracellular calcium level Cells were collected and loaded with $1 \mu \mathrm{M}$ Fluo-3AM (S1056; Beyotime Institute of Biotechnology, Nanjing, China), which combines with $\mathrm{Ca}^{2+}$ to produce strong fluorescence. According to the manufacturer protocols, after incubating for $30 \mathrm{~min}$ at $37^{\circ} \mathrm{C}$ in the dark, the cells were resuspended in $500 \mu \mathrm{L}$ phosphate buffer saline (PBS), and the fluorescence intensity was measured with an FACS Calibur flow cytometer (Becton-Dickinson, California, USA) at Ex./Em. wavelengths of $-488 / 525 \mathrm{~nm}$.

Detection of the intracellular ROS level Intracellular ROS levels were determined with the fluorescent dye DCFH-DA (KGT010-1; KeyGen Biotech, Nanjing, China) in accordance with the manufacturer's instructions. Treated cells were harvested, incubated with the corresponding dye and then evaluated on a flow cytometer (Becton-Dickinson Biosciences, New Jersey, USA).

\section{Flow cytometric analysis of apoptosis}

Cells were collected and processed with the Annexin V/PI Cell Apoptosis Detection Kit (Vazyme Biotec, Nanjing, China) for 10 min at room temperature in the dark, according to the kit protocols. Data acquisition and analysis were performed with a Becton-Dickinson FACS Calibur flow cytometer and CellQuest software. Cells stained with neither Annexin V nor PI were regarded as surviving cells.

Measurement of the mitochondrial membrane potential Cells were harvested after treatment with LW-213 and stained with $10 \mu \mathrm{M} \mathrm{JC}-1$ (KeyGen Biotech, Nanjing, China) in accordance with the manufacturer's protocol. Processed cells were analyzed by flow cytometry $(E x=488 \mathrm{~nm} ; \mathrm{Em}=530 \mathrm{~nm}$ ) in the FL-1 (green) and FL-2 (red) channels.

Mitochondria- and cytosol-enriched extracts

Following a $12 \mathrm{~h}$ incubation of cells with LW-213, mitochondrial/ cytosolic fractionation was performed using the Mitochondria/ Cytosol Fractionation Kit (Beyotime Institute of Biotechnology, Nanjing, China) according to the manufacturer's instructions.

Western blot analysis

Cells were harvested and washed twice with ice-cold PBS. The cells were lysed in RIPA buffer (Thermo Scientific, Massachusetts, USA) with protease inhibitors (PMSF, NaF, leupeptin, and dithiothreitol) on ice for $60 \mathrm{~min}$. The lysates were shaken every $30 \mathrm{~min}$. Then, the cell lysates were clarified by centrifugation at $12,000 \mathrm{rpm}$ (Eppendorf, Hamburg, Germany) for $30 \mathrm{~min}$ at $4^{\circ} \mathrm{C}$. The protein concentration in the supernatant was quantified with a BCA assay kit and a Varioskan multimode microplate spectrophotometer (Thermo, MA, USA).

Equal amounts of protein extracts were loaded for 10\% SDSpolyacrylamide gel electrophoresis and transferred to nitrocellulose membranes (BiTraceNT, PallCor). The membranes were 
blocked with $3 \%$ BSA in PBS at room temperature for $1 \mathrm{~h}$, incubated with a primary antibody diluted at the indicated ratio in PBST (phosphate buffer saline and $0.1 \%$ Tween-20) at $37^{\circ} \mathrm{C}$ for $1 \mathrm{~h}$, and then incubated overnight at $4^{\circ} \mathrm{C}$. The membranes were washed with PBST three times, and then incubated with an IRDyeTM800-conjugated secondary antibody for $55 \mathrm{~min}$ at $37^{\circ} \mathrm{C}$. After washing the membranes with PBST three times, and then with PBS one time for $10 \mathrm{~min}$ each time, detection was performed with the Odyssey Infrared Imaging System (Li-COR; Lincoln, NE).

Primary antibodies specific for PERK (5683T), elf2a (5324T), and p-elf2a (3398T) were obtained from Cell Signaling Technology (Danvers, MA). Antibodies against p-PERK (A16314), ATF4 (A0201), GRP78 (A0241), BAX (A0207), Bak-1 (A0204), death receptor 5 (DR5) (A1236), Caspase-8 (A0215), Caspase-3 (A2156), PARP-1 (A0942), COX-IV (A10098), Bcl-2 (A0208), and $\beta$-Actin (AC026) were obtained from ABclonal Technology (Wuhan, China). Antibodies against CHOP (SC-7351) and Caspase-9 (SC-73548) were purchased from Santa Cruz Biotechnology (Santa Cruz, CA, USA). An anti-Cytochrome-C antibody (66264-I-lg) was purchased from Proteintech. IRDye ${ }^{\mathrm{TM}} 800$-conjugated secondary antibodies were purchased from Rockland (Philadelphia, PA, USA).

\section{Antitumor effects on mice}

Female NOD/SCID immunodeficient mice (5-6 weeks old, weighing 18-22 g) (Beijing HFK Bioscience Co., Ltd., Beijing, China) were transplanted with Hut-102 cells. Animals were subcutaneously injected with $2 \times 10^{6}$ Hut- 102 cells in $0.1 \mathrm{~mL}$ saline. When tumors were palpable $\left(50-100 \mathrm{~mm}^{3}\right)$, the mice were divided randomly into three groups ( $n=5$ per group): a control group ( $0.9 \%$ normal saline), an NAB-treated group ( $200 \mathrm{mg} / \mathrm{kg}$ ) and an LW-213-treated group $(10 \mathrm{mg} / \mathrm{kg})$. Treatment was carried out by i.p. injection every other day for 14 days. At the end of the experiment, the animals were sacrificed, and the tumors were prepared for immunofluorescence assays.

Female NOD/SCID immunodeficient mice (6-9 weeks old) (Beijing HFK Bioscience Co., Ltd., Beijing, China) were sublethally irradiated $(1.8 \mathrm{~Gy})$ and engrafted with Hut-102 cells $\left(1 \times 10^{7}\right.$ cells per mouse, $n=6$ per group) via the tail vein $24 \mathrm{~h}$ after irradiation. After 7 days, the mice in the Hut-102 cell-bearing group were injected intraperitoneally with $0.9 \%$ normal saline, NAB $(200 \mathrm{mg} /$ $\mathrm{kg})$, CTX $(15 \mathrm{mg} / \mathrm{kg})$, or LW-213 $(10 \mathrm{mg} / \mathrm{kg})$ every 2 days. The animals were monitored daily.

\section{siRNA transfection}

CHOP siRNA was synthesized by Shanghai GenePharma Co., Ltd. Transfection was performed using Lipofectamine $2000^{\mathrm{TM}}$ reagent (Invitrogen, San Diego, CA) according to the manufacturer's instructions. The siRNA sense oligonucleotide for $C H O P$ was $5^{\prime}$ GCGCAUGAAGGAGAAAGAATT-3', and the antisense oligonucleotide was 5'-UUCUUUCUCCUUCAUGCGCTT-3'.

Quantitative real-time RT-qPCR

RT-qPCR was performed according to the manufacturer's instructions [29]. The primer sequences were as follows:

\section{GAPDH. Forward 5'-GCAGGGGGGAGCCAAAAGGG-3' Reverse 5'-TGCCAGCCCCAGCGTCAAAG-3'}

\section{CHOP. Forward 5'-CTGCCTITCACCTTGGAGAC-3'} Reverse 5'-ATAGAGTAGGGGTCCTITGC-3'

FACS analysis of bone marrow cells

Bone marrow cells were harvested and depleted of red blood cells using a red blood cell lysis buffer (eBioscience). For FACS analysis, cells were stained with anti-human CD45 antibodies at $4{ }^{\circ} \mathrm{C}$ for $30 \mathrm{~min}$. Centrifugation at $350 \times g$ and $4{ }^{\circ} \mathrm{C}$ for $5 \mathrm{~min}$ was performed to collect total cells, followed by resuspension of the cells in $500 \mu \mathrm{L}$ PBS and detection using an FACS Calibur flow cytometer. In this model, human $\mathrm{CD}_{4} 5^{+}$cells were defined as human leukocytes.

Immunofluorescence analysis

Immunofluorescence assays were performed as previously reported [30]. Images were captured with a confocal microscope at $\times 1000$ magnification (FV1000; Olympus, Tokyo, Japan).

Statistical analysis

All results are expressed as the mean \pm standard error of the mean. The data shown were obtained from triplicate independent parallel experiments. Statistical analyses of multiple group comparisons were performed by one-way analysis of variance followed by the Bonferroni post test. Comparisons between two groups were analyzed using two-tailed Student's $t$ tests. The significance of differences is indicated as ${ }^{*} P<0.05$ or ${ }^{* *} P<0.01$.

\section{RESULT}

LW-213 inhibited viability and induced cell apoptosis in CTCL cells Human CTCL cell lines (Hut-102, Hut-78, MyLa, and HH) were cultured in the absence or presence of LW-213 at various concentrations for 12 or $24 \mathrm{~h}$. We observed that LW-213 inhibited the viability of these CTCL cells (Fig. 1a). Compared with no treatment, treatment with LW-213 at concentrations ranging from 1 to $25 \mu \mathrm{M}$ induced significant inhibition of cell viability in a concentration- and time-dependent manner (Fig. 1a). The $I_{50}$ values of Hut-102, Hut-78, MyLa, and HH cells are displayed in Fig. 1b. Moreover, Ki67 expression was detected to evaluate cell viability. As shown in Fig. 1C, LW-213 inhibited the growth and viability of Hut-102 cells.

Apoptosis is a crucial programmed form of cell death occurring in aging or damaged cells [31]. We monitored cell apoptosis in CTCL cell lines (Hut-102, Hut-78, MyLa, and HH) after treatment with various concentrations of LW-213 for 12 or $24 \mathrm{~h}$ (Fig. $1 \mathrm{~d}$, e). The results showed that LW-213 induced apoptosis in these cells. Among the four cell lines, apoptosis induced by LW-213 was most obvious in Hut-102 cells, while apoptosis was least obvious in Hut78 cells. We further observed the effect of $12 \mathrm{~h}$ of LW-213 treatment on primary leukemia cells derived from the peripheral blood of T-cell lymphoma patients. The results showed that the percentage of apoptotic cells increased dramatically (Table 1, Fig. 1f).

LW-213 increased the intracellular calcium level in CTCL cells There is a growing consensus that calcium $\left(\mathrm{Ca}^{2+}\right)$ is a ubiquitous second messenger involved in the control of a broad variety of physiological events, including apoptosis [32]. Therefore, we examined the effect of LW-213 on the intracellular $\mathrm{Ca}^{2+}$ level in Hut-102 and Hut-78 cells. Cells were exposed to LW-213 (15 $\mu \mathrm{M})$ for different durations. Upregulation of the intracellular $\mathrm{Ca}^{2+}$ level was observed at $0.5 \mathrm{~h}$ in Hut-102 cells. The intracellular $\mathrm{Ca}^{2+}$ level peak (10.05 \pm 0.56$)$ was observed at $24 \mathrm{~h}$. However, in Hut-78 cells, the intracellular $\mathrm{Ca}^{2+}$ level began to increase after treatment with LW-213 for $9 \mathrm{~h}$. After treatment with $15 \mu \mathrm{M}$ LW-213 for $24 \mathrm{~h}$, the intracellular calcium concentration increased by $3.32 \pm 0.34$-fold (Fig. 2a). The results above suggested that the LW-213-induced increase in the intercellular $\mathrm{Ca}^{2+}$ concentration was slower and gentler in Hut-78 cells than in Hut-102 cells. We then examined the intracellular $\mathrm{Ca}^{2+}$ levels in other CTCL cell lines. The results showed that LW-213 increased the intracellular $\mathrm{Ca}^{2+}$ level in Hut102, Hut-78, MyLa, and HH cells in a time- and dose-dependent manner (Fig. 2c).

We suspected that the source of $\mathrm{Ca}^{2+}$ was the $\mathrm{ER}$, the main $\mathrm{Ca}^{2+}$ repository in eukaryotes. $\mathrm{IP}_{3}$ receptor $\left(\mathrm{IP}_{3} \mathrm{R}\right)$ is an important $\mathrm{Ca}^{2+}$ channel located in the ER [33]. We measured the apoptosis rate after cotreatment with LW-213 and 2-aminoethyl 

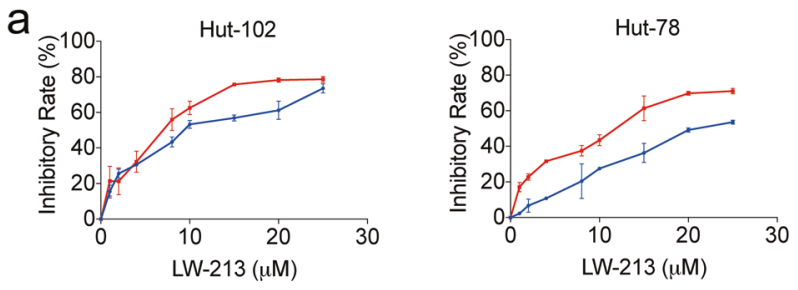

b

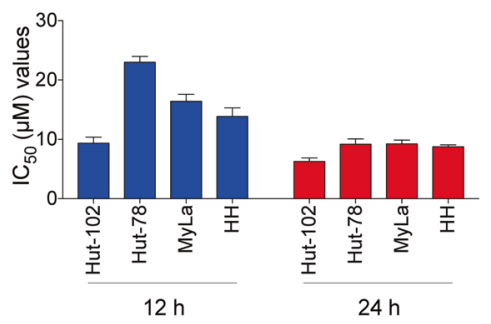

d

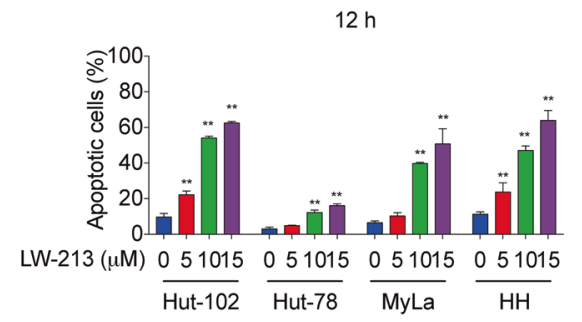

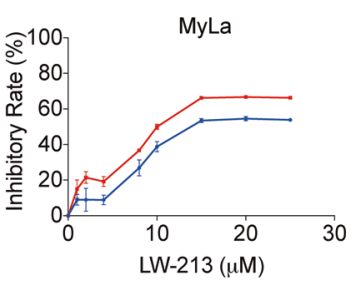

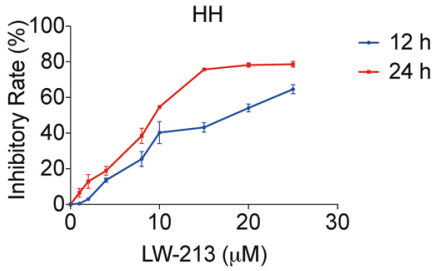

Hut-102

C

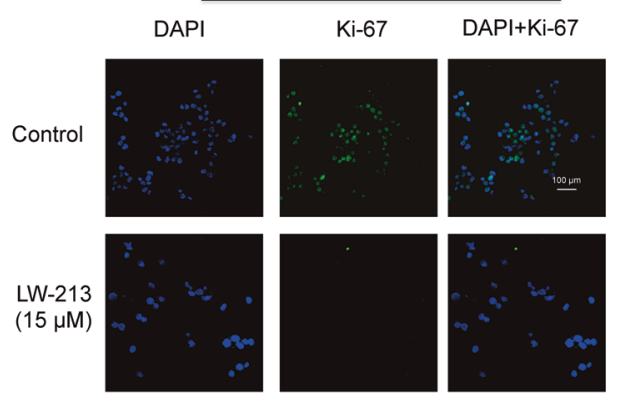

e

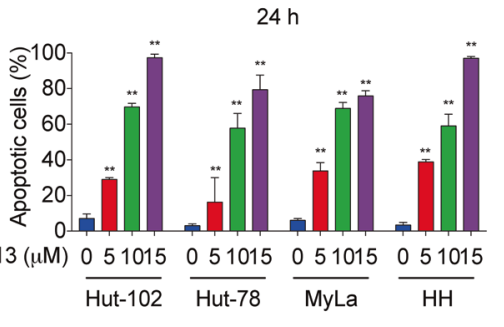

f

\#1

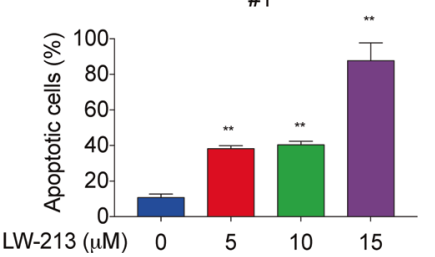

\# 2

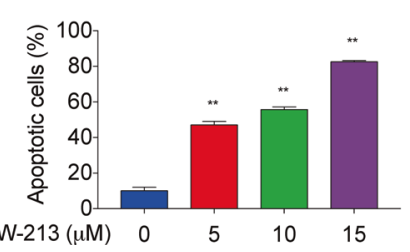

\# 3

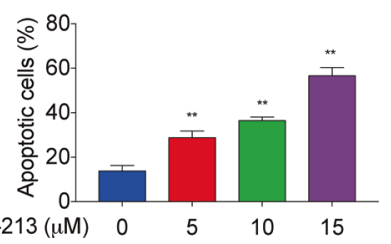

Fig. 1 LW-213 inhibited cell viability and induced cell apoptosis in CTCL cells. a The growth inhibition effect of LW-213 on Hut-102, Hut-78, MyLa, and HH cells was assessed by a CCK8 assay at 12 and $24 \mathrm{~h}$. b The IC $\mathrm{I}_{50}$ values of LW-213 for Hut-102, Hut-78, MyLa, and HH cells at 12 and $24 \mathrm{~h}$ are shown. c The cell proliferation of Hut-102 cells was detected by Ki67 staining after treatment with $15 \mu \mathrm{M}$ LW-213. Green fluorescence indicates Ki67 expression, while nuclei were stained with DAPI. Cells were evaluated by confocal microscopy (FV1000; Olympus) with FV10-ASW2.1 acquisition software (Olympus) at room temperature (original magnification $\times 1000$; immersion objective $\times 100 / \times 40$ with immersion oil type). Images are representative of three independent experiments. d, e Flow cytometric analysis of Annexin V-FITC/PI-PerCPstained CTCL cell lines (Hut-102, Hut-78, MyLa, and HH) treated with 5, 10, and $15 \mu \mathrm{M} \mathrm{LW-213}$ for 12 and $24 \mathrm{~h}$ was performed. f Primary samples $(1,2$, and 3$)$ were treated with LW-213 $(0,5,10$, and $15 \mu \mathrm{M})$ for $12 \mathrm{~h}$, and apoptotic cells were evaluated by flow cytometric analysis of Annexin V-FITC/PI-PerCP staining. Data are shown as the mean \pm S.E.M. of three independent experiments. Two-tailed $P$ values were calculated; ${ }^{*} P<$ $0.05,{ }^{* *} P<0.01$.

Table 1. Clinical data for patient samples with T-lymphoma.

\begin{tabular}{|c|c|c|c|c|c|c|}
\hline Patient no. & Diagnosis & Source & WBC $\left(\times 10^{9}\right)$ & Cytogenetics & Naïve lymphocyte & Status \\
\hline 1 & T-cell lymphoma & PB & 4.0 & OD & $97.8 \%$ & New \\
\hline 2 & T-cell lymphoma & PB & 185.1 & Notch1, Wnt1 & $87.0 \%$ & New \\
\hline
\end{tabular}


a

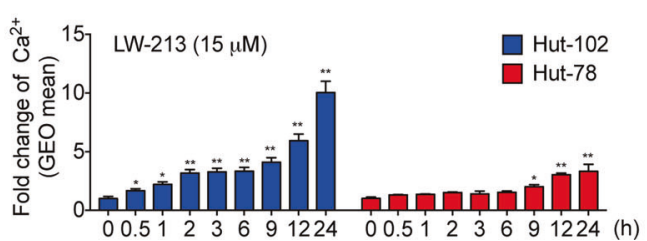

b

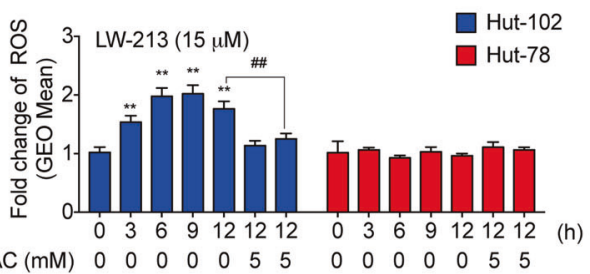

C

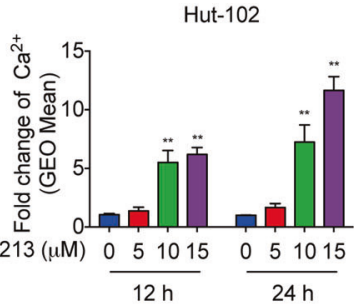

Hut-78

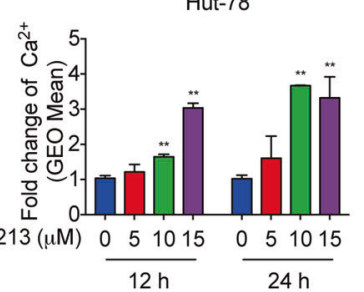

d

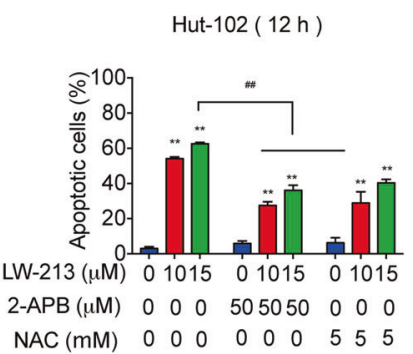

$\mathrm{HH}$
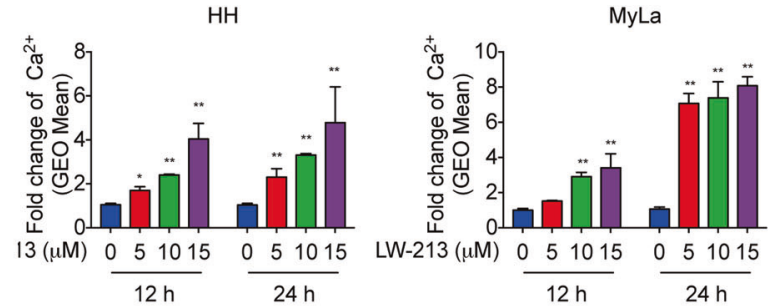

e

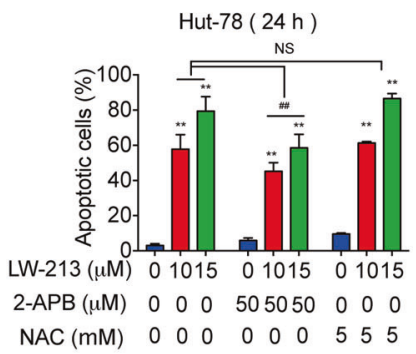

$\mathrm{f}$
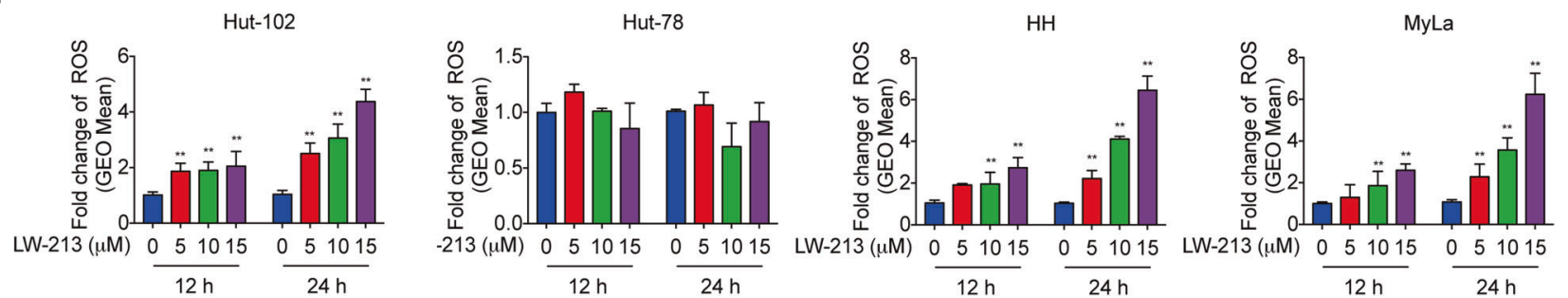

Fig. 2 LW-213 increased the intracellular levels of calcium and ROS in CTCL cells. a Hut-102 and Hut-78 cells were treated with $15 \mu \mathrm{M}$ LW213 for $0.5,1,2,3,6,9,12$, and $24 \mathrm{~h}$. Flow cytometric analysis of Hut-102 and Hut-78 cells stained with the Ca ${ }^{2+}$ indicator Fluo-3AM was performed. The fold changes in fluorescence intensity values (\% of control) were calculated. b Cells were preincubated with/without NAC $(5 \mathrm{mM})$ for $1 \mathrm{~h}$, and then exposed to $15 \mu \mathrm{M} \mathrm{LW}-213$ for 3, 6, 9, or $12 \mathrm{~h}$. Flow cytometric analysis of the fluorescence intensity of ROS was performed. The fold changes in ROS fluorescence intensity values (\% of control) were calculated. c Hut-102, Hut-78, HH, and MyLa cells were treated with 5, 10, and $15 \mu \mathrm{M} \mathrm{LW}-213$. Flow cytometric analysis of these cells stained with the $\mathrm{Ca}^{2+}$ indicator Fluo-3 AM was performed. The fold changes in fluorescence intensity values (\% of control) were calculated. d Hut-102 cells were pretreated with/without NAC (5 mM) or 2-APB $(50 \mu \mathrm{M})$ and incubated with 10 or $15 \mu \mathrm{M} \mathrm{LW}-213$ for $12 \mathrm{~h}$. Apoptotic cells were detected by flow cytometry. e Hut-78 cells were pretreated with/without NAC ( $5 \mathrm{mM})$ or 2-APB $(50 \mu \mathrm{M})$ and incubated with 10 or $15 \mu \mathrm{M} \mathrm{LW}-213$ for $24 \mathrm{~h}$. Apoptotic cells were detected by flow cytometry. f Hut-102, Hut-78, HH, and MyLa cells were treated with 5, 10 and $15 \mu \mathrm{M} \mathrm{LW}-213$ for 12 and 24 h. Flow cytometric analysis of the fluorescence intensity of ROS was performed. The fold changes in ROS intensity values (\% of control) were calculated. Data are shown as the mean \pm S.E.M. of three independent experiments. Two-tailed $P$ values were calculated; ${ }^{*} P<0.05,{ }^{* *} P<0.01$, NS not significant.

diphenylborinate (2-APB), an $\mathrm{IP}_{3} \mathrm{R}-1$ inhibitor, to explore whether LW-213-induced apoptosis involves the influx of extracellular $\mathrm{Ca}^{2+}$ [34]. At $12 \mathrm{~h}, \mathrm{LW}-213$-induced apoptosis could be reversed significantly by 2 -APB $(50 \mu \mathrm{M})$, and the 10 and $15 \mu \mathrm{M}$ LW-213induced apoptosis rates of Hut-102 cells decreased from $54.13 \% \pm$ $0.54 \%$ and $62.57 \% \pm 0.45 \%$ to $36.11 \% \pm 1.67 \%$ and $27.53 \% \pm$ $1.28 \%$, respectively, (Fig. 2 d). In Hut-78 cells, at $24 \mathrm{~h}$, the 10 and 15 $\mu \mathrm{M}$ LW-213-induced apoptosis rates decreased from $57.81 \% \pm$ $5.82 \%$ and $79.40 \% \pm 4.73 \%$ to $45.20 \% \pm 2.83 \%$ and $58.51 \% \pm$ $4.46 \%$, respectively, (Fig. $2 \mathrm{~d}$ ). The results described above showed that LW-213-induced cell apoptosis had a positive correlation with the increase in the intercellular $\mathrm{Ca}^{2+}$ concentration in Hut-102, MyLa, $\mathrm{HH}$, and Hut-78 cells (Fig. 2e).
LW-213 increased intracellular ROS levels in all CTCL cells tested except Hut-78 cells

We further examined whether LW-213 induces the formation of ROS in CTCL cells. We exposed Hut-78 and Hut-102 cells to $15 \mu \mathrm{M}$ LW-213 for different times, and then the fluorescence intensity was detected to assess the levels of ROS. The results showed that the fluorescence intensity increased in Hut-102 cells, peaking in cells treated for $9 \mathrm{~h}$, which showed a doubling of the ROS level compared with untreated cells (Fig. 2b). Meanwhile, we chose Nacetyl cysteine (NAC), an ROS scavenger that potently decreases ROS levels, to reduce the elevation. Our data showed that pretreatment with NAC $(5 \mathrm{mM})$ for $1 \mathrm{~h}$ prominently mitigated the LW-213-triggered ROS increase in Hut-102 cells (Fig. 2b). However, 
in the same situation, LW-213 did not increase the ROS fluorescence intensity of Hut-78 cells (Fig. 2b). We then examined the changes in ROS levels after treatment with LW-213 in other CTCL cell lines. The results showed that LW-213 increased ROS levels in Hut-102, MyLa, and HH cells but not those in Hut-78 cells in a time- and dose-dependent manner (Fig. $2 \mathrm{f}$ ).

Then, we evaluated the effect of ROS on LW-213-induced apoptosis. In Hut-102 cells pretreated with NAC for $1 \mathrm{~h}$, cell apoptosis was decreased compared with that in cells treated with LW-213 alone. However, in Hut-78 cells, pretreatment with NAC hardly influenced LW-213-induced apoptosis (Fig. 2d, e). The results described above showed that LW-213-induced cell apoptosis had a positive correlation with the increase in ROS levels in Hut-102, MyLa, and HH cells but not in Hut-78 cells.

LW-213 activated the PERK-eIF2a-ATF4 signaling axis to lead to upregulation of CHOP expression in CTCL cells

The ER, which is a characteristic intracellular $\mathrm{Ca}^{2+}$ storage compartment, is a major organoid in the regulation of the intrinsic pathways that execute apoptosis [35]. PERK functions as an ER transmembrane sensor that detects unfolded or misfolded proteins and associates with GRP78 in its inactive form, which is mediated by inactivation of elF2a $[36,37]$. To determine whether LW-213-induced apoptosis is mediated by ER stress in CTCL cells, several ER stress-associated molecules were examined by an immunofluorescence staining assay and Western blot analysis. First, the expression of GRP78, a gatekeeper of the activation of ER stress transducers, increased after LW-213 treatment in Hut-102 cells [38]. In addition, the expression levels of p-PERK (Thr981), pelF2a (Ser51), and ATF4 were tested. the levels of these proteins were increased in the Hut-102 cell line, but no significant changes were found in the total PERK and elF2a levels (Fig. 3a-c). Furthermore, the changes in these proteins could be alleviated by 2-APB and NAC (Fig. 3b, c).

Apoptosis occurs when the functions of the ER are severely impaired, and the activation of CHOP is one of the apoptotic pathways involved in this event [39]. Thus, the expression of $\mathrm{CHOP}$ in Hut-102 cells was evaluated by an immunofluorescence assay, revealing that LW-213 induced strong $\mathrm{CHOP}$ expression in the cytoplasm and nucleus (Fig. 3a). Western blot results showed the same phenomenon (Fig. 3b, c). To verify the importance of ER stressinduced CHOP expression in cell apoptosis induced by LW-213, $C H O P$ was silenced by using siRNA, and the efficiency of transfection is shown in Fig. 3d. Transfection with CHOP siRNA led to a significant decrease in Hut-102 cell apoptosis induced by LW-213 (Fig. 3e).

These results indicated that LW-213 selectively activated CHOP and induced apoptosis by activating the PERK-elF2a-ATF4 pathway, which is an ER stress-dependent apoptosis signaling pathway in CTCL cell lines.

LW-213 induced intrinsic and extrinsic apoptosis in CTCL cells Apoptosis is a key regulator of physiological homeostasis that is divided into two categories: intrinsic and extrinsic apoptotic pathways [40, 41]. To determine the mechanism underlying LW213-induced apoptosis in Hut-102 cells, we identified several widespread elements involved in the extrinsic and intrinsic pathways.

As a significant index for early apoptosis, the mitochondrial membrane potential $\left(\Delta \Psi_{\mathrm{m}}\right)$ was assessed by using JC-1 staining of Hut-102 cells. As shown in Fig. $4 \mathrm{a}$, b, exposure to LW-213 for $12 \mathrm{~h}$ resulted in the collapse of the $\Delta \Psi_{\mathrm{m}}$ in a concentration-dependent manner, indicating a remarkable incremental decrease in the $\Delta \Psi_{\mathrm{m}}$ in LW-213-treated cells. In addition, LW-213 decreased the expression of $\mathrm{BCl}-2$ and increased the expression of Bax and Bak-1. Furthermore, we noticed prominent activation of caspase-9 (Fig. 4c, d). As an important mitochondrial inner membraneassociated protein, cytochrome-c plays a key role in caspasedependent apoptosis upon release into the cytoplasm. After treatment with LW-213 for $12 \mathrm{~h}$, the amount of cytochrome-c in the mitochondria was notably reduced, but the amount in the cytosol was increased (Fig. 4e, f). DR5 is an apoptosis-inducing membrane receptor for tumor necrosis factor-related apoptosisinducing ligand [42]. CHOP is involved in ER stress-induced apoptosis by enhancing DR5 expression in human carcinoma cells [43]. Our results showed that after treatment with LW-213 for $12 \mathrm{~h}$, the expression of DR5 increased, leading to the activation of caspase-8 (Fig. 4g, h). The modulatory effects of the apoptotic pathway, including changes in the expression of caspase- 3 and PARP-1, were also examined. Data obtained by Western blot analysis showed that LW-213 induced the cleavage of caspase-3 and PARP- 1 in a concentration-dependent manner (Fig. $4 i, j$ ). Furthermore, $50 \mu \mathrm{M}$ 2-APB or $5 \mathrm{mM}$ NAC cotreatment with $15 \mu \mathrm{M}$ LW-213 partially reversed the changes in these proteins observed in Hut-102 cells, suggesting that apoptosis induced by LW-213 may be associated with the observed increases in the intracellular $\mathrm{Ca}^{2+}$ and ROS levels (Fig. 4c, d, g-j).

LW-213 exhibited antitumor activity in vivo

To further evaluate the antitumor effects of LW-213 in vivo, a Hut102 cell line-derived xenograft model was established using NOD/ SCID mice (Fig. 5a). After administration of NAB ( $200 \mathrm{mg} / \mathrm{kg})$, a pan HDAC inhibitor, or LW-213 $(10 \mathrm{mg} / \mathrm{kg})$ every other day for 2 weeks, the mice were sacrificed. LW-213 showed significant inhibitory effects on the growth of xenograft tumors (Fig. 5b). The weight and volume of resected tumors in the LW-213-treated group were obviously lower than those in the untreated group (Fig. 5c, d). In addition, immunofluorescence results showed that the expression of CHOP and GRP78 was increased in the Hut-102 cell-derived xenografts of the LW-213-treated group compared with those of the control group. In addition, NAB administration mildly increased this expression (Fig. 5e, f).

Then, we constructed NOD/SCID mouse models engrafted with Hut-102 cells via the tail vein. After administration of NAB (200 $\mathrm{mg} / \mathrm{kg})$, a pan HDAC inhibitor, LW-213 $(10 \mathrm{mg} / \mathrm{kg})$ and cyclophosphamide (CTX) $(15 \mathrm{mg} / \mathrm{kg})$ every other day for 4 weeks, bone marrow cells were collected and evaluated by using FACS analysis. Compared with that of the blank group, the population of human $\mathrm{CD}_{4} 5^{+}$cells in the bone marrow of the Hut-102 tumor-bearing group was increased conspicuously. In the LW-213-treated group, the population of human $\mathrm{CD} 45^{+}$cells was decreased (Fig. $5 \mathrm{~g}$ ). In addition, CTX and LW-213 noticeably prolonged the survival of Hut-102 cell-bearing mice compared with control mice (Fig. 5h). Finally, hematoxylin and eosin (HE) staining showed that the LW213-treated group displayed fewer visceral injuries than the control group (Fig. 5i).

\section{DISCUSSION}

Natural products constitute a promising intervention to prevent, inhibit or reverse the processes of carcinogenesis [44]. Flavonoids, such as baicalein, wogonin, and oroxylin A, are characterized by antitumor activity and can be used to produce new drugs with effective anticancer activity [45-47]. LW-213, a newly synthesized flavonoid, induces apoptosis in CML cells [28]. In this study, we found that LW-213 showed antiproliferative and apoptotic effects on CTCL cell lines. Moreover, LW-213 inhibited the proliferation of Hut-102-derived xenografts and prolonged survival in Hut-102 cell-bearing mice in vivo.

There is a growing consensus that $\mathrm{Ca}^{2+}$ is an important second messenger involved in an array of biological events. Fine tuning of intracellular $\mathrm{Ca}^{2+}$ homeostasis is linked to the regulation of apoptosis [32]. Previous research has shown that wogonin kills malignant $\mathrm{T}$ lymphocytes by triggering $\mathrm{Ca}^{2+}$-dependent apoptosis [48]. To this end, we suspected that LW-213 influences the level of intracellular $\mathrm{Ca}^{2+}$. We hypothesized that the increase in the $\mathrm{Ca}^{2+}$ level resulted from release from the ER, the major $\mathrm{Ca}^{2+}$ repository 


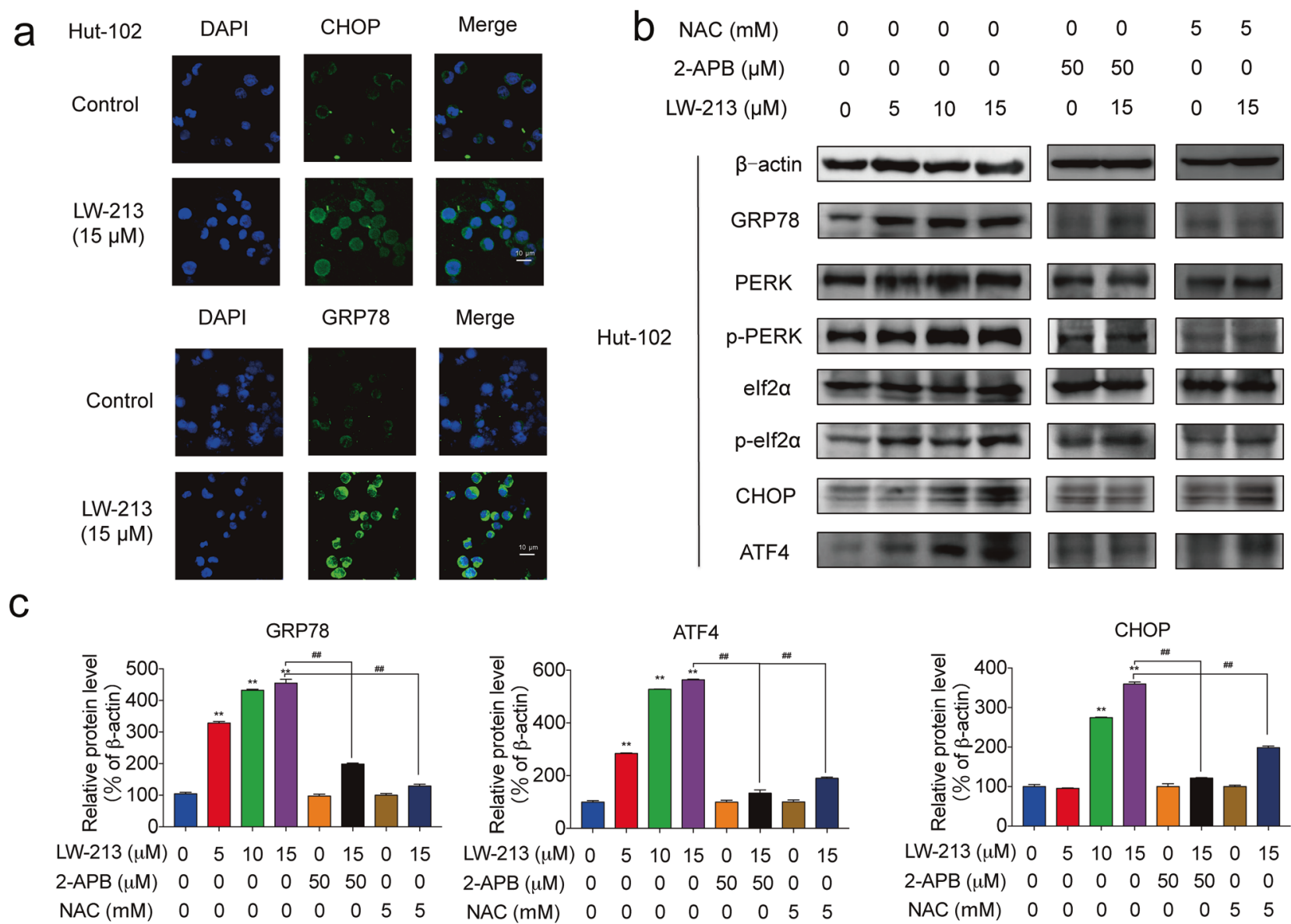

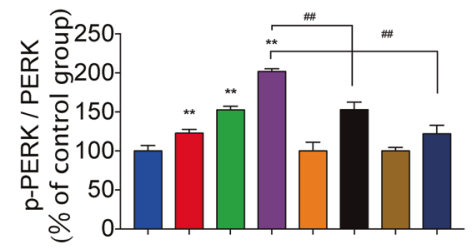

LW-213 $(\mu M) \quad 0 \quad 5 \quad 1015 \quad 0 \quad 15 \quad 0 \quad 15$

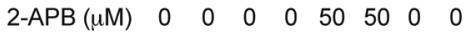

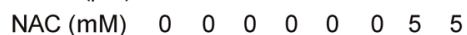

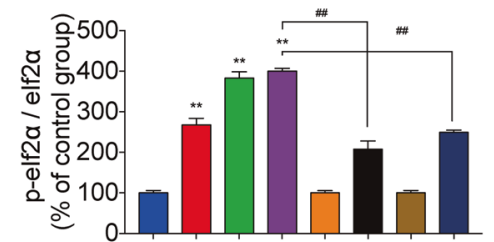

LW-213 $(\mu \mathrm{M}) \quad 0 \quad 5 \quad 10 \quad 15 \quad 0 \quad 15 \quad 0 \quad 15$

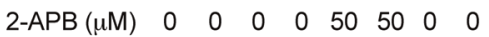

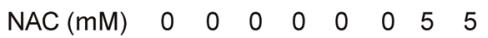

\section{d}

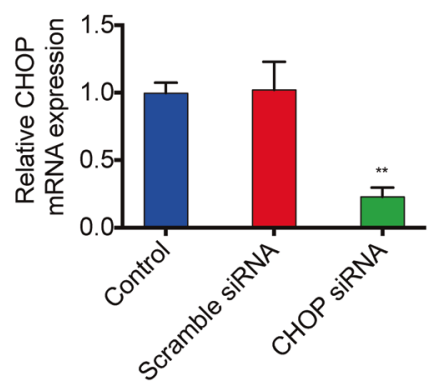

e

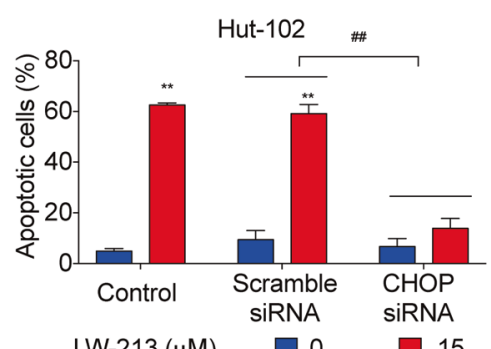

Fig. 3 LW-213 activated the PERK-elF2a-ATF4 signaling axis in CTCL cells. a Immunofluorescence staining assays for CHOP and GRP78 were performed to test the effect of $12 \mathrm{~h}$ of LW-213 treatment $(15 \mu \mathrm{M})$ on Hut-102 cells. Green fluorescence indicates CHOP or GRP78 expression, while nuclei were stained with DAPI. Cells were evaluated by confocal microscopy (FV1000; Olympus) with FV10-ASW2.1 acquisition software (Olympus) at room temperature (original magnification $\times 1000$; immersion objective $\times 100 / \times 60$ with immersion oil type). Images are representative of three independent experiments. b, c Hut-102 cells were treated with 5,10 , or $15 \mu \mathrm{M}$ LW-213 for $12 \mathrm{~h}$ or pretreated with/without NAC (5 mM) or 2-APB $(50 \mu \mathrm{M})$, and then incubated with $15 \mu \mathrm{M} \mathrm{LW}-213$ for $12 \mathrm{~h}$. The expression levels of PERK-elF2 $\alpha-A T F 4$ signaling axis-related proteins were analyzed by Western blot analysis. $\beta$-actin was used as a loading control. d The transfection efficacy of CHOP siRNA in Hut-102 cells was detected by RTqPCR. e Hut-102 cells were transfected with CHOP siRNA, and then treated with LW-213 $(15 \mu \mathrm{M})$ for $12 \mathrm{~h}$. Apoptotic cells were detected by flow cytometry. Data are shown as the mean \pm S.E.M. of three independent experiments. Two-tailed $P$ values were calculated; ${ }^{* * P}<0.01 .{ }^{\# \# P}<0.05$. 
a

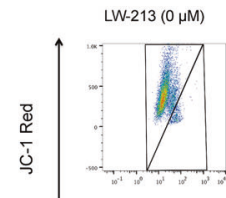

LW-213 (5 $\mu \mathrm{M})$

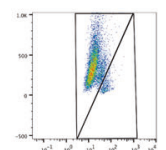

$\mathrm{LW}-213(10 \mu \mathrm{M})$

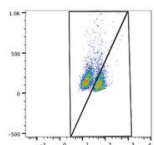

LW-213 $(15 \mu \mathrm{M})$

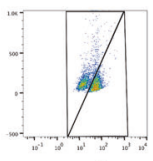

b

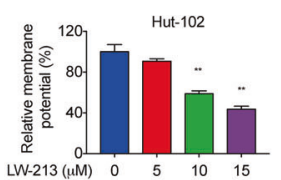

C

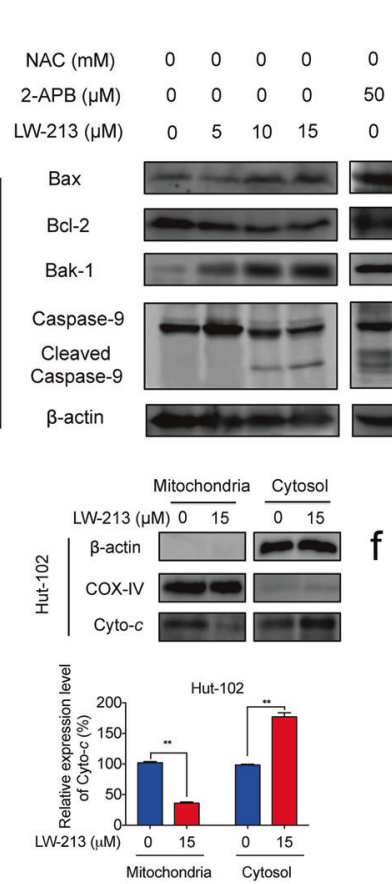

JC-1 Green
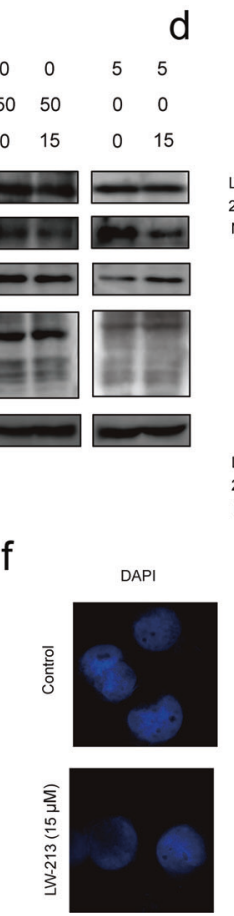
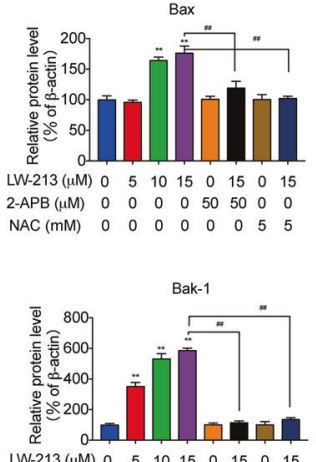

LW-213 $(\mu \mathrm{M}) \quad 0 \quad \begin{array}{llllllll}5 & 10 & 15 & 0 & 15 & 0 & 15\end{array}$

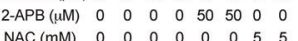

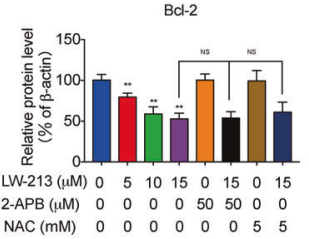

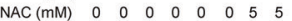

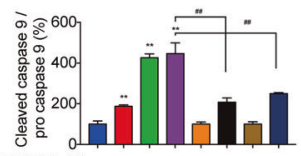

LW-213 (uM) $0 \quad 5 \quad 1015 \quad 0 \quad 150015$ 2-APB $(\mu M) \quad 0 \quad 00010505000$

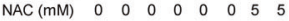
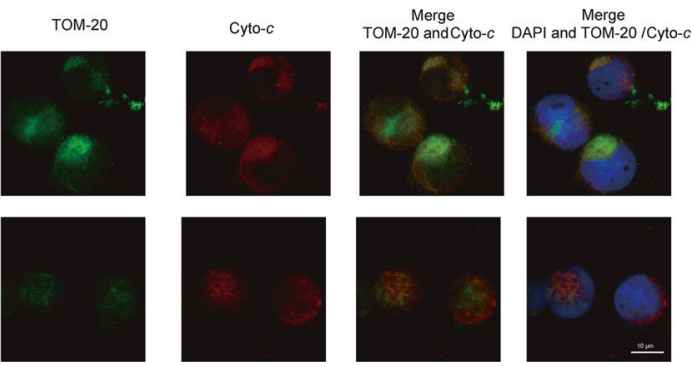

g

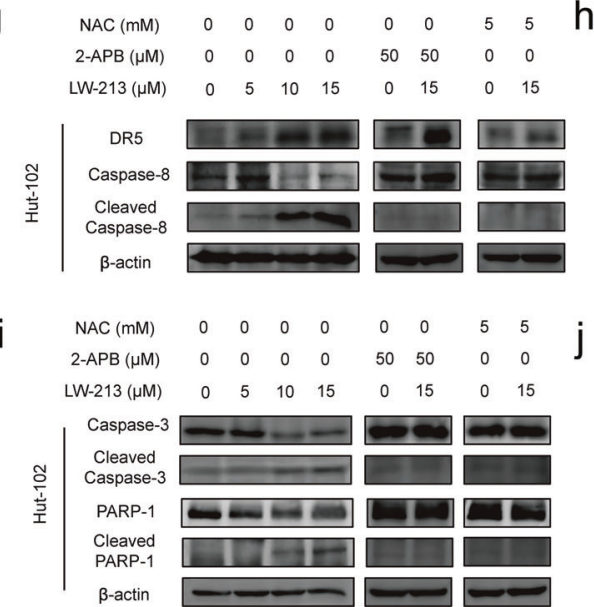

$\mathrm{h}$
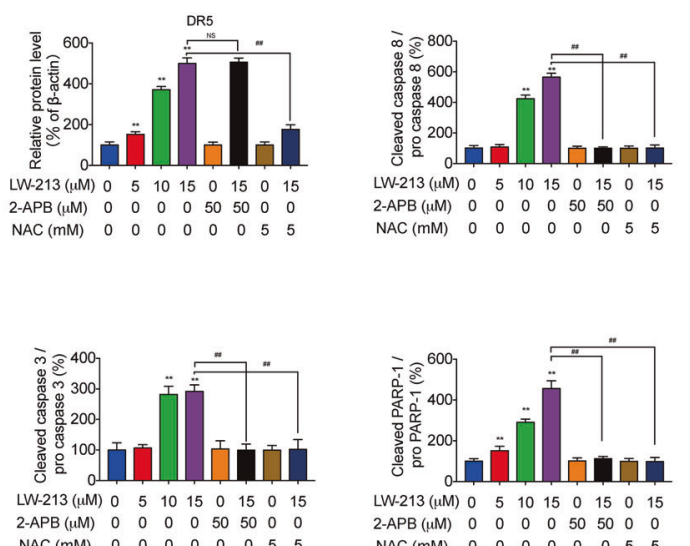

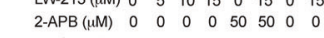
NAC (mM) $\quad 0 \begin{array}{lllllllll} & 0 & 0 & 0 & 0 & 0 & 5 & 5\end{array}$

Fig. 4 LW-213 induced intrinsic and extrinsic apoptosis in CTCL cells. a, b Hut-102 cells were treated with $15 \mu \mathrm{M}$ LW-213 for $12 \mathrm{~h}$, and the changes in the $\Delta \Psi \mathrm{m}$ of Hut-102 cells were detected by JC- 1 staining and analyzed by flow cytometry. The relative $\Delta \Psi \mathrm{m}$ was calculated as the ratio of red fluorescence in treated cells to that in DMSO control cells. c, d Hut-102 cells were pretreated with/without NAC (5 mM) and 2-APB $(50 \mu \mathrm{M})$, and then incubated with 5,10 , or $15 \mu \mathrm{M} \mathrm{LW}-213$ for $12 \mathrm{~h}$. The expression levels of apoptosis-associated proteins were analyzed by Western blot analysis. $\beta$-actin was used as a loading control. e Hut-102 cells were treated with $15 \mu \mathrm{M} \mathrm{LW-213}$ for $12 \mathrm{~h}$, and the effect of LW-213induced cytochrome-c release was analyzed by mitochondrial and cytosolic fractionation assays. COX-IV was used as a loading control for the mitochondrial fraction, and $\beta$-actin was used as a loading control for the cytosolic fraction. $\mathbf{f}$ Hut-102 cells were treated with $15 \mu \mathrm{M}$ LW-213 for $12 \mathrm{~h}$, and the effect of LW-213-induced cytochrome-c release was analyzed by an immunofluorescence staining assay. Mitochondria were stained with TOM-20 (green fluorescence), red fluorescence indicates cytochrome-c, and nuclei were stained with DAPI. Cells were evaluated by confocal microscopy (FV1000; Olympus) with FV10-ASW2.1 acquisition software (Olympus) at room temperature (original magnification $\times 1000$; immersion objective $\times 100 / \times 100$ with immersion oil type). Images are representative of three independent experiments. $\mathbf{g}$-j Hut102 cells were treated with 5,10 , or $15 \mu \mathrm{M} \mathrm{LW}-213$ for $12 \mathrm{~h}$ or pretreated with/without NAC (5 mM) or 2-APB (50 $\mu \mathrm{M})$, and then incubated with $15 \mu \mathrm{M} \mathrm{LW}-213$ for $12 \mathrm{~h}$. The expression levels of apoptosis-associated proteins were analyzed by Western blot analysis. $\beta$-actin was used as a loading control. ${ }^{* *} P<0.05$. ${ }^{\# \#} P<0.05$. 
a

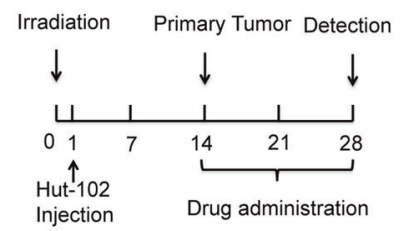

C

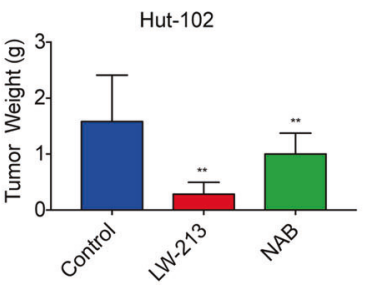

e

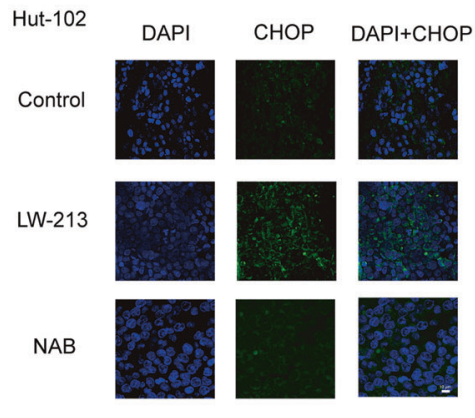

g

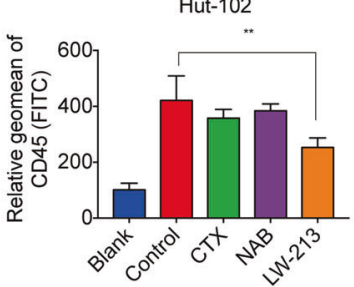

i

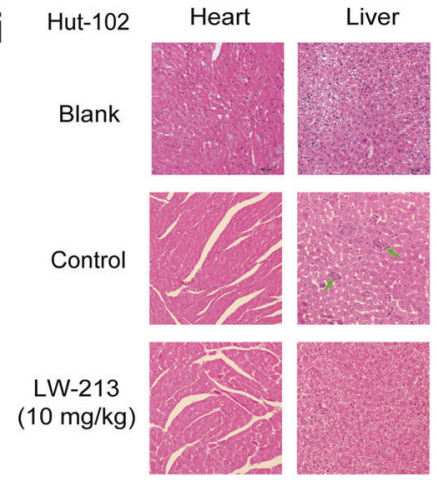

b

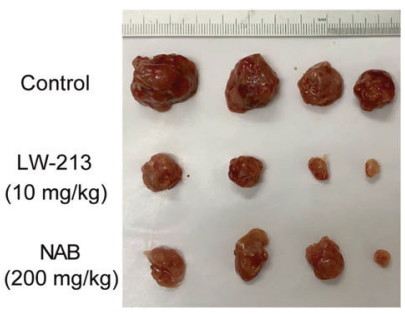

d
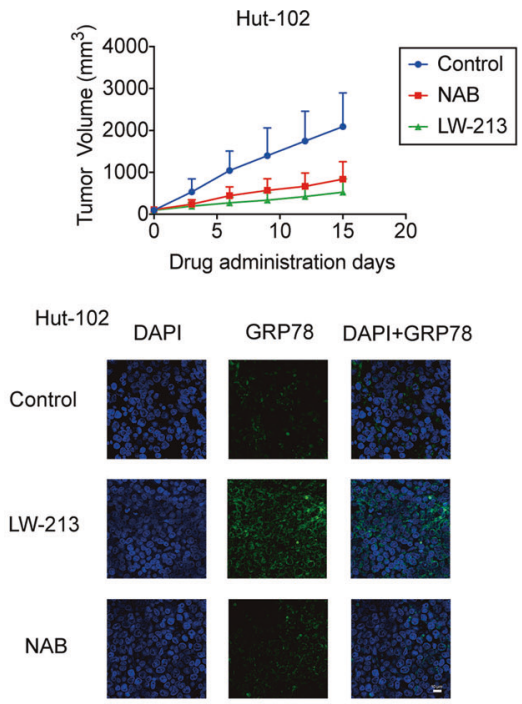

h

Hut-102
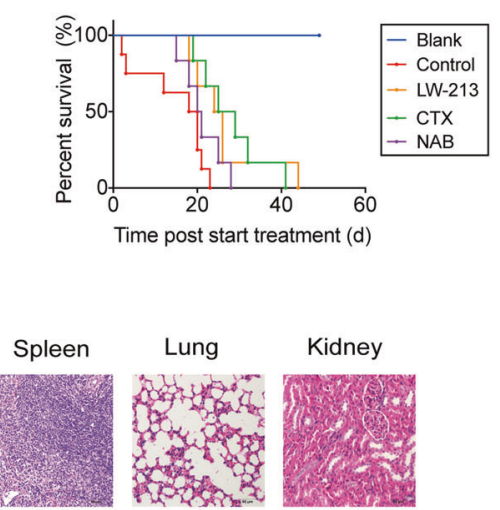

Kidney
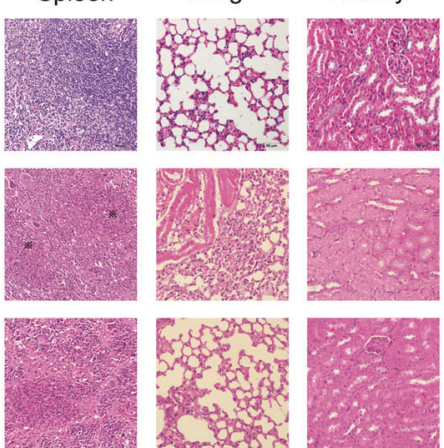

Fig. 5 LW-213 exhibited antitumor activity in vivo. a A flowchart for evaluation of the effect on Hut-102 cell-bearing NOD/SCID mouse xenograft models is shown. b-d The effects of NAB and LW-213 on the xenograft tumor growth of Hut-102 cell-bearing NOD/SCID mice were investigated. e, $\mathbf{f}$ The expression of GRP78 and CHOP in xenograft tumor tissue samples from Hut-102 cell-bearing mice was revealed by immunofluorescence. Green fluorescence indicates CHOP or GRP78 expression, while nuclei were stained with DAPI. Cells were evaluated by confocal microscopy (FV1000; Olympus) with FV10-ASW2.1 acquisition software (Olympus) at room temperature (original magnification $\times 1000$; immersion objective $\times 100 / \times 60$ with immersion oil type). $\mathbf{g}$ The huCD45 expression of bone marrow cells from Hut-102 cell-bearing mice in each group was examined by flow cytometry analyses. Data represent the mean \pm S.E.M. of three independent experiments. Asterisks denote statistically significant $\left({ }^{*} P<0.05 ;{ }^{* *} P<0.01\right)$ differences between treated mice and control mice determined by one-way ANOVA. h Kaplan-Meier survival plots of Hut-102 cell-bearing NOD/SCID mice are shown. i Mice were sacrificed after LW-213 treatment, and their tissues were resected and fixed in $4 \%$ formalin for $\mathrm{HE}$ analysis. Images were acquired at $\times 20$ magnification. Green arrows represent extramedullary hemopoiesis, and black labels represent cell infiltration. 


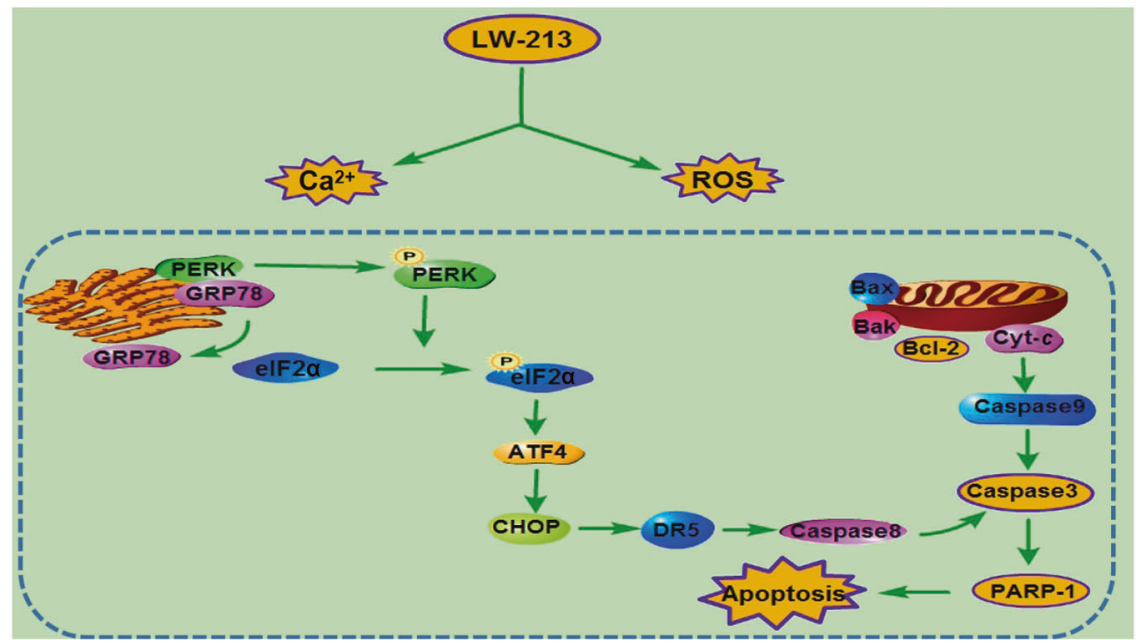

Fig. 6 Possible mechanisms underlying the apoptosis-inducing effect of LW-213 on CTCL cells.

in eukaryotes. IP3R is an important $\mathrm{Ca}^{2+}$ channel located in the ER [33]. We found that apoptosis induced by LW-213 could be alleviated by an IP3R-1 inhibitor, suggesting that LW-213-induced cell apoptosis was associated with an increase in the intracellular calcium level and that the increase in the intracellular $\mathrm{Ca}^{2+}$ level may come from the ER via the IP3R channel (Fig. 6).

Evidence is increasing that ROS, a key player in oxidative stress, play momentous, and extensive roles in pathways involved in cell proliferation, apoptosis, and death [49]. In addition, ROS is a critical mediator of ER dysfunction [50]. Many drugs and natural products that modulate ROS generation regulate ER stress [51, 52]. It has been well established that the regulation of ROS serves as an important effect of wogonin treatment $[53,54]$. In this study, we placed special emphasis on clarifying the participation of ROS in the antitumor effect of LW-213. We found that LW-213 increased the level of ROS and induced apoptosis in Hut-102, MyLa, and HH cells. In addition, both ROS production and apoptosis caused by LW-213 could be alleviated by the antioxidant NAC, which confirmed that the antitumor effect of LW-213 was associated with oxidative stress in the above cell lines.

However, LW-213 did not increase the formation of ROS in Hut78 cells, a cell line derived from the peripheral blood of patients with SS that constitutively express high levels of the activated form of NF-KB [55]. In NF-KB-activated cells, the generation of ROS is suppressed by the mitochondrial enzyme $\mathrm{Mn}^{2+}$ superoxide dismutase (Mn-SOD) [56]. To this end, Hut-78 cells may not be sensitive to changes in ROS levels. The ER is a multifunctional cellular organelle that is responsible for the synthesis, folding, and posttranslational modification of proteins, and it is a component that tightly regulates oxidation and $\mathrm{Ca}^{2+}$ homeostasis [33]. ER stress is a cellular condition of imbalance between the protein folding load and capacity of the ER [57]. Once ER stress becomes severe and homeostasis cannot be reestablished, the apoptotic pathway is activated $[7,58]$. PERK is a mediator of force-induced apoptosis required to disrupt ER calcium homoeostasis [59]. PERK-elF2a-ATF4 is a major signaling pathway in ER stress. Previous research suggests that PERK is required at ERmitochondrial contact sites to convey apoptotic signaling after ROS-based ER stress [15]. Therefore, we examined the PERK-elF2a-ATF4 signaling axis in CTCL cells. We found that LW213 activated this signaling axis and induced the expression of downstream $\mathrm{CHOP}$, one of the vital components involved in $\mathrm{ER}$ stress-induced apoptosis.

Taken together, our results illustrated the involvement of intracellular calcium and ROS in LW-213-induced apoptosis. We further demonstrated that LW-213 could induce apoptosis in CTCL cells by activating PERK-elF2a-ATF4 signaling. These findings indicate that regulation of ER stress is responsible for the anticancer effects of LW-213 and suggest the potential of developing LW-213 into a novel agent for CTCL treatment.

\section{ACKNOWLEDGEMENTS}

This work was supported by the National Natural Science Foundation of China (81873046, 81830105, 81903647, 81503096, and 81673461), the Drug Innovation Major Project (2017ZX09301014, 2018ZX09711001-003-007, and 2017ZX09101003005-023), Natural Science Foundation of Jiangsu Province (BK20190560 and BE2018711), Nanjing Medical Science and Technology Development Project (YKK17074), Research and Innovation Project for College Graduates of Jiangsu Province (KYCX18 0803), China Postdoctoral Science Foundation (No. 2018M642373), and "Double First-Class" University project (CPU 2018GF11 and CPU2018GF05).

\section{AUTHOR CONTRIBUTIONS}

$\mathrm{XXY}$ designed and performed research, analyzed data, and wrote the paper; $\mathrm{HL}$ and MYZ performed research and analyzed data; PH and JRW performed research; YJQ and XYW collected data and performed statistical analysis; HZW and ZYW collected and analyzed data; JYX provided the blood samples; and QG and HH conceptualized the project and directed the experimental design and data analysis.

\section{ADDITIONAL INFORMATION}

Competing interests: The authors declare no competing interests.

\section{REFERENCES}

1. Khadhar A, Chelly I, Zehani A, Litaiem N, Zaraa I, Azouz $\mathrm{H}$, et al. A challenging cutaneous T-cell lymphoma. Am J Dermatopathol. 2016;38:63-5.

2. Ryan A. Cutaneous T-cell lymphoma: 2017 update on diagnosis, risk-stratification, and management. Am J Hematol. 2017;92:1085-102.

3. Quaglino $P$, Maule $M$, Prince HM, Porcu P, Horwitz $S$, Duvic $M$, et al. Global patterns of care in advanced stage mycosis fungoides/Sezary syndrome: a multicenter retrospective follow-up study from the Cutaneous Lymphoma International Consortium. Ann Oncol. 2017;28:2517-25.

4. Bagherania N, Bruce R. An overview of cutaneous T cell lymphomas. F1000Res. 2016;5:F1000.

5. Sam T, John E, Elaine $S$, Wyndham $H$. Mycosis fungoides and Sézary syndrome. Lancet. 2008;371:945-57.

6. Ryan A. Hematology, cutaneous T-cell lymphoma: 2014 update on diagnosis, riskstratification, and management. Am J Hematol. 2014;89:837-51.

7. Verfaillie T, Abhishek D, Patrizia A. Targeting ER stress induced apoptosis and inflammation in cancer. Cancer Lett. 2013;332:249-64.

8. Maurel M, Eoghan P, Mnich K, Healy S, Chevet E, Samali A. Controlling the unfolded protein response-mediated life and death decisions in cancer. Semin Cancer Biol. 2015;33:57-66. 
9. Mori K. The unfolded protein response: the dawn of a new field. Proc Jpn Acad Ser B Phys Biol Sci. 2015;91:469-80.

10. Wang M, Randal J. The impact of the endoplasmic reticulum protein-folding environment on cancer development. Nat Rev Cancer. 2014;14:581-97.

11. Madden E, Susan E, Sandra J, Manie S, Samali A. The role of the unfolded protein response in cancer progression: from oncogenesis to chemoresistance. Biol Cell. 2019;111:1-17.

12. Ching-Fen W, JeongSeo E, Sabine M, Klauck, Efferth T. Cryptotanshinone deregulates unfolded protein response and eukaryotic initiation factor signaling in acute lymphoblastic leukemia cells. Phytomedicine. 2016;23:174-80.

13. Cosenza M, Civallero M, Fiorcari S, Pozzi S, Marcheselli L, Bari A, et al. The histone deacetylase inhibitor romidepsin synergizes with lenalidomide and enhances tumor cell death in T-cell lymphoma cell lines. Cancer Biol Ther. 2016;17:1094-106.

14. Mengxiong W, Mary E, Ronald K, Brian K. The unfolded protein response as a target for anticancer therapeutics. Crit Rev Oncol Hematol. 2018;127:66-79.

15. Verfaillie T, Rubio N, Garg A, Bultynck G, Rizzuto R, Decuypere J, et al. PERK is required at the ER-mitochondrial contact sites to convey apoptosis after ROSbased ER stress. Cell Death Differ. 2012;19:1880-91.

16. Rozpedek W, Pytel D, Mucha B, Leszczynska H, Diehl J, Majsterek I. The role of the PERK/elF2a/ATF4/CHOP signaling pathway in tumor progression during endoplasmic reticulum stress. Curr Mol Med. 2016;16:533-44.

17. Zong ZH, Du ZX, Li N, Li C, Zhang Q, Liu BQ, et al. Implication of Nrf2 and ATF4 in differential induction of CHOP by proteasome inhibition in thyroid cancer cells. Biochim Biophys Acta. 2012;1823:1395-404.

18. Clarke HJ, Chambers JE, Liniker E, Marciniak SJ. Endoplasmic reticulum stress in malignancy. Cancer Cell. 2014;25:563-73.

19. Cabrera E, Hernández-Pérez $S$, Koundrioukoff $S$, Debatisse $M$, Kim DB, Smolka M, et al. PERK inhibits DNA replication during the unfolded protein response via claspin and Chk1. Oncogene. 2017;36:678-86.

20. Singh M, Uman S, Shukla Y. New enlightenment of skin cancer chemoprevention through phytochemicals: in vitro and in vivo studies and the underlying mechanisms. Biomed Res Int. 2014;2014:2434-52. https://doi.org/10.1155/2014/ 243452.

21. Mao XY, Jin MZ, Chen JF, Zhou HH, Jin WL. Live or let die: neuroprotective and anti-cancer effects of nutraceutical antioxidants. Pharmacol Ther. 2018;183:137-51.

22. Huang AC, Chang CL, Yu CS, Chen PY, Yang JS, Ji BC, et al. Induction of apoptosis by curcumin in murine myelomonocytic leukemia WEHI-3 cells is mediated via endoplasmic reticulum stress and mitochondria-dependent pathways. Environ Toxicol. 2013;28:255-66.

23. Heo JR, Kim SM, Hwang KA, Kang JH, Choi KC. Resveratrol induced reactive oxygen species and endoplasmic reticulum stress-mediated apoptosis, and cell cycle arrest in the A375SM malignant melanoma cell line. Int J Mol Med. 2018;42:1427-35

24. Davalli P, Rizzi F, Caldara G, Davoli S, Corti A, Silva A, et al. Chronic administration of green tea extract to TRAMP mice induces the collapse of Golgi apparatus in prostate secretory cells and results in alterations of protein post-translational processing. Int J Oncol. 2011;39:1521-7.

25. Gongbo L, Sakina M, Nonn L, Jeremy J. Inhibition of CHOP accentuates the apoptotic effect of a-mangostin from the mangosteen fruit (Garcinia mangostana) in 22Rv1 prostate cancer cells. Biochem Biophys Res Commun. 2014:453:75-80

26. Huang X, Li L, Zhang L, Zhang Z, Wang X, Zhang X, et al. Crosstalk between endoplasmic reticulum stress and oxidative stress in apoptosis induced by atocopheryl succinate in human gastric carcinoma cells. $\mathrm{Br} J$ Nutr. 2013;109:727-35.

27. Zhao L, Miao HC, Li WJ, Sun Y, Huang SL, Li ZY, et al. LW-213 induces G2/M cell cycle arrest through AKT/GSK3 $\beta / \beta$-catenin signaling pathway in human breast cancer cells. Mol Carcinog. 2016;55:778-92.

28. Liu X, Hu P, Li H, Yu XX, Wang XY, Qing YJ, et al. LW-213, a newly synthesized flavonoid, induces $\mathrm{G}_{2} / \mathrm{M}$ phase arrest and apoptosis in chronic myeloid leukemia. Acta Pharmacol Sin. 2020;41:249-59.

29. Ping J, Li JT, Liao ZX, Shang L, Wang H. Indole-3-carbinol inhibits hepatic stellate cells proliferation by blocking NADPH oxidase/reactive oxygen species/p38 MAPK pathway. Eur J Pharmacol. 2011;650:656.

30. Li H, Yu X, Liu X, Hu P, Shen L, Zhou Y, et al. Wogonoside induces depalmitoylation and translocation of PLSCR1 and N-RAS in primary acute myeloid leukaemia cells. J Cell Mol Med. 2018;22:2117-30.

31. Cotter T. Apoptosis and cancer: the genesis of a research field. Nat Rev Cancer. 2009:9:501-7.

32. Pinton P, Giorgi C, Siviero R, Zecchini E, Rizzuto R. Calcium and apoptosis: ERmitochondria $\mathrm{Ca}^{2+}$ transfer in the control of apoptosis. Oncogene. 2008;27:6407-18.
33. Krebs J, Agellon L, Michalak M. $\mathrm{Ca}^{2+}$ homeostasis and endoplasmic reticulum (ER) stress: an integrated view of calcium signaling. Biochem Biophys Res Commun. 2015;460:114-21.

34. Yamada N, Makino Y, Clark R, Pearson D, Mattei M, Guénet J, et al. Human inositol 1,4,5-trisphosphate type-1 receptor, InsP3R1: structure, function, regulation of expression and chromosomal localization. Biochem J. 1994;302:781-90.

35. Logue S, Cleary P, Saveljeva S, Samali A. New directions in ER stress-induced cell death. Apoptosis. 2013;18:537-46.

36. Mengxiong W, Mary E, Castellano R, Brian K. The unfolded protein response as a target for anticancer therapeutics. Crit Rev Oncol Hematol. 2018;127:66-79.

37. Rozpedek W, Pytel D, Mucha B, Leszczynska H, Diehl J, Majsterek I. The role of the PERK/elF2a/ATF4/CHOP signaling pathway in tumor progression during endoplasmic reticulum stress. Curr Mol Med. 2016;16:533-44.

38. Wu Y, Zhang H, Dong Y, Park YM, Ip C. Endoplasmic reticulum stress signal mediators are targets of selenium action. Cancer Res. 2005;65:9073-9.

39. Oyadomari S, Mori M. Roles of CHOP/GADD153 in endoplasmic reticulum stress. Cell Death Differ. 2004;11:381-9.

40. Thomas G. Apoptosis and cancer: the genesis of a research field. Nat Rev Cancer. 2009;9:501-7.

41. Portt L, Norman G, Clapp C, Greenwood M, Greenwood M. Anti-apoptosis and cell survival: a review. Biochim Biophys Acta. 2011;1813:238-59.

42. Shetty S, Gladden J, Henson E, Hu X, Villanueva J, Haney N, et al. Tumor necrosis factor-related apoptosis inducing ligand (TRAIL) up-regulates death receptor 5 (DR5) mediated by NFKB activation in epithelial derived cell lines. Apoptosis. 2002;7:413-20.

43. Yamaguchi $H$, Wang HG. CHOP is involved in endoplasmic reticulum stressinduced apoptosis by enhancing DR5 expression in human carcinoma cells. J Biol Chem. 2004;279:45495-502.

44. Singletary K. Diet, natural products and cancer chemoprevention. J Nutr. 2000;130:465S-6S

45. Wu R, Murali R, Kabe Y, French SW, Chiang YM, Liu S, et al. Baicalein targets GTPase-mediated autophagy to eliminate liver tumor-initiating stem cell-like cells resistant to mTORC1 inhibition. Hepatology. 2018;68:1726-40.

46. Dürr C, Hanna B, Schulz A, Lucas F, Zucknick M, Benner A, et al. TNF recetor signaling is a driver of chronic lymphocytic leukemia that can be therapeutically targeted by the flavonoid wogonin. Haematologica. 2018;103:688-97.

47. Litao Z, Li Z, Hu W, Yu W, Di P, Jing Y, et al. Oroxylin A reverses P-glycoproteinmediated multidrug resistance of MCF7/ADR cells by $G_{2} / M$ arrest. Toxicol Lett. 2013;219:107-15.

48. Baumann S, Stefanie C, Giaisi M, Müller W, Merling A, Gülow K, et al. Wogonin preferentially kills malignant lymphocytes and suppresses T-cell tumor growth by inducing PLCgamma1- and $\mathrm{Ca}^{2+}$-depend ent apoptosis. Blood. 2008;111:2354-63.

49. Kohanski M, Dwyer D, Hayete B, Lawrence $C$, Collins J. A common mechanism of cellular death induced by bactericidal antibiotics. Cell. 2007;130:797-810.

50. Bhandary B, Marahatta A, Kim $\mathrm{H}$, Chae $\mathrm{H}$. An involvement of oxidative stress in endoplasmic reticulum stress and its associated diseases. Int J Mol Sci. 2012;14:434-56.

51. Zhou $Y$, Shu F, Liang $X$, Chang $H$, Shi L, Peng $X$, et al. Ampelopsin induces cell growth inhibition and apoptosis in breast cancer cells through ROS generation and endoplasmic reticulum stress pathway. PLoS One. 2014;9:e89021.

52. Choi A, Hyun J, Hwang K, Jeong Y, Choe W, Yoon K, et al. Licochalcone A induces apoptosis through endoplasmic reticulum stress via a phospholipase $\mathrm{C}^{1-}, \mathrm{Ca}^{2+}$, and reactive oxygen species-dependent pathway in HepG2 human hepatocellular carcinoma cells. Apoptosis. 2014;19:682-97.

53. Yang L, Wang Q, Li D, Zhou Y, Zheng X, Sun H, et al. Wogonin enhances antitumor activity of tumor necrosis factor-related apoptosis-inducing ligand in vivo through ROS-mediated downregulation of CFLIPLand IAP proteins. Apoptosis. 2013;18:618-26.

54. Tsai CF, Yeh WL, Huang SM, Tan TW, Lu DY. Wogonin induces reactive oxygen species production and cell apoptosis in human glioma cancer cells. Int J Mol Sci. 2012:13:9877-92.

55. Giri D, Aggarwal B. Constitutive activation of NF-kappaB causes resistance to apoptosis in human cutaneous T cell lymphoma HuT-78 cells: autocrine role of tumor necrosis factor and reactive oxygen intermediates. J Biol Chem. 1998;273:14008-14.

56. Bubici C, Papa S, Pham C, Zazzeroni F, Franzoso G. The NF-kappaB-mediated control of ROS and JNK signaling. Histol Histopathol. 2006;21:69-80.

57. Schröder M, Randal J. ER stress and the unfolded protein response. Mutat Res. 2005;569:29-63.

58. Sano R, Reed J. ER stress-induced cell death mechanisms. Biochim Biophys Acta. 2013;1833:3460-70.

59. Liang SH, Zhang W, McGrath BC, Zhang P, Cavener DR. PERK (elF2alpha kinase) is required to activate the stress-activated MAPKs and induce the expression of immediate-early genes upon disruption of ER calcium homoeostasis. Biochem J. 2006;393:201-9. 